\title{
Longitudinal Changes in Insulin Resistance in Normal Weight, Overweight and Obese Individuals
}

\author{
Alice Tang ${ }^{1,2,+}$, Adelle C. F. Coster ${ }^{3,+} \mathbb{1}$, Katherine T. Tonks ${ }^{1,2,4}$, Leonie K. Heilbronn ${ }^{5}$, \\ Nicholas Pocock ${ }^{2}$, Louise Purtell ${ }^{1}$, Matthew Govendir ${ }^{1}$, Jackson Blythe ${ }^{1,2}{ }^{1}$, Jialiang Zhang ${ }^{6}$, \\ Aimin $X \mathbf{u}^{6}$, Donald J. Chisholm ${ }^{1,2}$, Nathan A. Johnson ${ }^{7}$, Jerry R. Greenfield ${ }^{1,2,4, *}$ and \\ Dorit Samocha-Bonet $1,2, *$ (i) \\ 1 Diabetes and Metabolism Division, Garvan Institute of Medical Research, Sydney 2010, Australia; \\ a.tang@unswalumni.com (A.T.); k.tonks@garvan.org.au (K.T.T.); louise.purtell@qut.edu.au (L.P.); \\ m.govendir@unsw.edu.au (M.G.); jackson.blythe@outlook.com (J.B.); d.chisholm@garvan.org.au (D.J.C.) \\ 2 \\ St. Vincent's Clinical School, UNSW Sydney, Sydney 2010, Australia; n.pocock@unsw.edu.au \\ School of Mathematics and Statistics, UNSW Sydney, Sydney 2052, Australia; A.Coster@unsw.edu.au \\ Department of Endocrinology and Diabetes Center, St. Vincent's Hospital, Sydney 2010, Australia \\ Adelaide Medical School, University of Adelaide, Adelaide 5005, Australia; \\ leonie.heilbronn@adelaide.edu.au \\ 6 State Key Laboratory of Pharmaceutical Biotechnology, The University of Hong Kong, Hong Kong, China; \\ hjzhang@hku.hk (J.Z.); amxu@hku.hk (A.X.) \\ 7 Faculty of Health Sciences, The University of Sydney, Camperdown 2006, Australia; \\ nathan.johnson@sydney.edu.au \\ * Correspondence: j.greenfield@garvan.org.au (J.R.G.); d.samochabonet@garvan.org.au (D.S.-B.); \\ Tel.: +61-292-958-309 (D.S.-B.) \\ + These authors contributed equally to this work.
}

Received: 11 April 2019; Accepted: 30 April 2019; Published: 8 May 2019

\begin{abstract}
Background: Large cohort longitudinal studies have almost unanimously concluded that metabolic health in obesity is a transient phenomenon, diminishing in older age. We aimed to assess the fate of insulin sensitivity per se over time in overweight and obese individuals. Methods: Individuals studied using the hyperinsulinaemic-euglycaemic clamp at the Garvan Institute of Medical Research from 2008 to $2010(n=99)$ were retrospectively grouped into Lean (body mass index (BMI) $<25 \mathrm{~kg} / \mathrm{m}^{2}$ ) or overweight/obese (BMI $\geq 25 \mathrm{~kg} / \mathrm{m}^{2}$ ), with the latter further divided into insulin-sensitive $\left(\mathrm{Ob}_{\mathrm{Sen}}\right)$ or insulin-resistant $\left(\mathrm{Ob}_{\mathrm{Res}}\right)$, based on median clamp M-value (M/I, separate cut-offs for men and women). Fifty-seven individuals participated in a follow-up study after $5.4 \pm 0.1$ years. Hyperinsulinaemic-euglycaemic clamp, dual-energy X-ray absorptiometry and circulating cardiovascular markers were measured again at follow-up, using the same protocols used at baseline. Liver fat was measured using computed tomography at baseline and proton magnetic resonance spectroscopy at follow-up with established cut-offs applied for defining fatty liver. Results: In the whole cohort, M/I did not change over time $(p=0.40)$; it remained significantly higher at follow-up in $\mathrm{Ob}_{\text {Sen }}$ compared with $\mathrm{Ob}_{\text {Res }}(p=0.02)$, and was not different between $\mathrm{Ob}_{\text {Sen }}$ and Lean $(p=0.41)$. While BMI did not change over time $(p=0.24)$, android and visceral fat increased significantly in this cohort ( $\left.p_{\text {time }} \leq 0.0013\right)$, driven by $\operatorname{Ob}_{\text {Res }}(p=0.0087$ and $p=0.0001$, respectively). Similarly, systolic blood pressure increased significantly over time $\left(\mathrm{p}_{\text {time }}=0.0003\right)$ driven by $\mathrm{Ob}_{\text {Res }}$ $(p=0.0039)$. The best correlate of follow-up M/I was baseline M/I (Spearman's $r=0.76, p=1.1 \times 10^{-7}$ ). Conclusions: The similarity in insulin sensitivity between the $\mathrm{Ob}_{\mathrm{Sen}}$ and the Lean groups at baseline persisted over time. Insulin resistance in overweight and obese individuals predisposed to further metabolic deterioration over time.
\end{abstract}

Keywords: insulin resistance; obesity; fat-free mass; hyperinsulinaemic-euglycaemic clamp; liver fat 


\section{Introduction}

The obesity rate has nearly tripled worldwide since 1975, with World Health Organization data indicating that in 2016,39\% of adults were overweight and 13\% were obese [1]. In the United States, recent figures indicate that $40 \%$ of adults are obese, with the obesity rate in the 40-60 year old age group exceeding $40 \%$ [1].

While obesity is a risk factor for metabolic disease, sub cohorts with obesity not complicated by the metabolic syndrome have been described. These so called "metabolically healthy obese" may have reduced risk of type 2 diabetes, cardiovascular disease and all-cause mortality compared with individuals with obesity and the metabolic syndrome [2]. The criteria used to define metabolically healthy obesity (MHO) varies widely across studies. With at least 30 different definitions applied, the prevalence of MHO ranged from 6 to $75 \%$ in the obese population [3]. Most studies included blood pressure, high density lipoprotein (HDL) cholesterol, fasting plasma glucose and/or triglyceride in their definition. Less than half included the insulin resistance surrogate homeostatic model assessment of insulin resistance (HOMA-IR), and less than one-third included diabetes [3]. Compared to the use of the metabolic syndrome criteria to sub-categorise obesity, fewer studies have used insulin sensitivity per se (that is, sub-categorisation into insulin-sensitive obesity $\left(\mathrm{Ob}_{\mathrm{Sen}}\right)$ and insulin-resistant obesity $\left.\left(\mathrm{Ob}_{\text {Res }}\right)\right)$. Most studies considering insulin resistance used the insulin resistance surrogate homeostatic model assessment of insulin resistance (HOMA-IR) [3]; some smaller cohort studies used the gold-standard hyperinsulinaemic-euglycaemic clamp $[4,5]$.

Despite having a better metabolic health profile compared to the metabolically unhealthy obesity group, longitudinal studies with diabetes and cardiovascular disease endpoints reported that MHO individuals held an intermediate health status, such that they were still worse off than the healthy normal weight individuals [6]. Moreover, recent longitudinal studies have shown that a large proportion of MHO progress to the unhealthy category over time [7-14]. Predictors of loss of metabolic health in MHO include older age $[9,15]$ and poorer cardio-metabolic risk at baseline, including lower HDL [9,11-13], higher triglycerides [11-13], higher central adiposity [11,15] and insulin resistance [9,11-13].

While there have been studies evaluating the stability of the MHO phenotype over time, to our knowledge no study has reported the durability of insulin-sensitivity per se, measured by the gold-standard hyperinsulinaemic-euglycaemic clamp in overweight and obese individuals. Focusing on the change in insulin resistance over time is key to dissecting the mechanism underlying the development of cardio-metabolic disease in individuals at risk. In the present study, we aimed to trace the change in insulin resistance, and to uncover predictors of insulin resistance in older age. The secondary aims were to trace the change in body composition, fat distribution and metabolic markers over time in a well-phenotyped cohort studied approximately 5 years apart.

\section{Experimental Section}

\subsection{Participants}

The Insulin Sensitivity in Obesity Study (ISOS) was approved by the St Vincent's Hospital Human Research Ethics Committee and the Garvan Institute of Medical Research Governance Office and registered at ClinicalTrials.gov (NCT02017210).

Participants of two previous separate studies performed at the Garvan Institute of Medical Research (Darlinghurst, NSW, Australia) [16,17] were contacted by postal mail to gauge interest in participating in a follow-up study. At the time of these previous studies ("baseline studies"), participants agreed to be contacted in the future for other potential studies, but were not contacted during the gap between the baseline and follow-up studies. The data collected in the original studies, performed between 2008 and 2010, formed the baseline data. In the original studies, exclusion criteria included weight change greater than $2 \mathrm{~kg}$ in the preceding 6 months, self-reported regular exercise for periods longer than $60 \mathrm{~min} /$ week, treatment with medications known to affect insulin sensitivity or carbohydrate metabolism, known renal, cardiac, or liver disease and current cancer, 
women planning pregnancy, consumption of more than 20 and $40 \mathrm{~g} /$ day alcohol for women and men, respectively, and smoking $>10$ cigarettes/day. Type 2 diabetes was defined by medical history or by fasting blood glucose $(\geq 7.0 \mathrm{mmol} / \mathrm{L})$ and/or 2-h blood glucose $(\geq 11.1 \mathrm{mmol} / \mathrm{L})$ following a $75 \mathrm{~g}$ oral glucose tolerance test (OGTT), which was performed during screening [17]. Non-diabetic participants from the baseline cohort $(n=99$, Figure 1 (Consort Diagram)) had their interest for participating in a follow-up study gauged by postal mail. Four were of Asian descent, the rest were Caucasian. Of the baseline participants, 25 were uncontactable or living interstate, 12 declined, 3 had a medical condition precluding participation in the follow-up study, 1 was actively losing weight, and 1 had passed away (Figure 1). Fifty-seven individuals were invited to the Clinical Research Facility for a screening visit to assess their medical status, and, if willing, progress to an additional study visit, which included detailed phenotyping, as described below. Sixteen individuals who were screened at follow-up did not progress to the detailed phenotyping study, 7 as they had lost interest and 9 due to medical conditions (Figure 1).

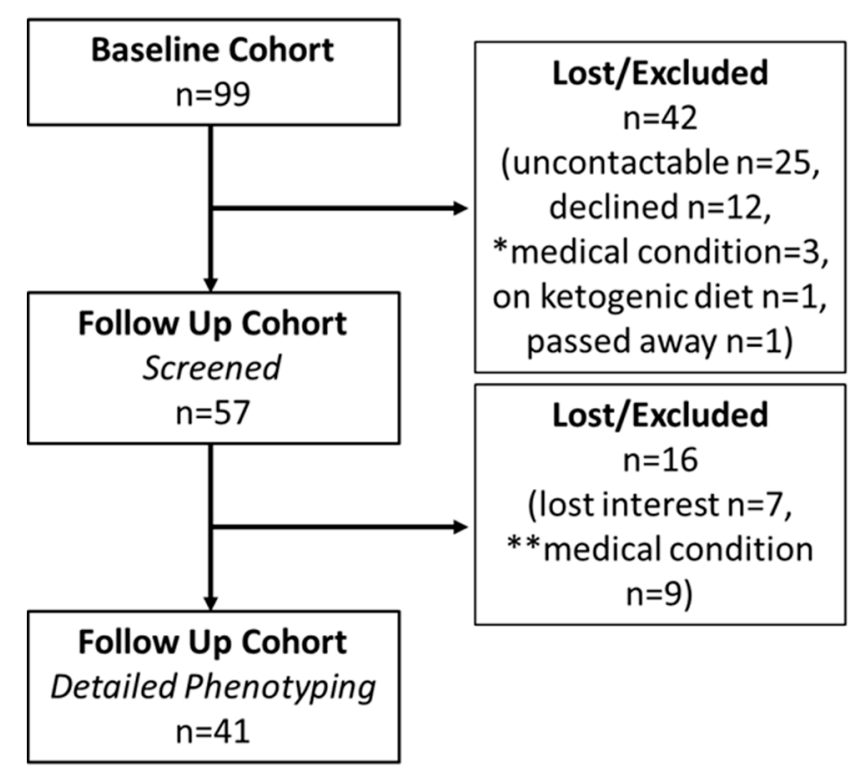

Figure 1. Study Flow (Consort Diagram). * Medical conditions precluding from follow-up screening included bowel cancer, mitral valve repair and cardiac arrhythmia, chronic lymphocytic lymphoma, breast cancer on letrozole, non-Hodgkin's lymphoma, sleeve gastrectomy and trying to conceive. ** Medical conditions precluding from detailed phenotyping included tetralogy of fallot, venous thrombotic disease, venous access difficulty (axillary lymph node clearance), iron deficiency anemia of uncertain cause, significant coronary artery disease (requiring stenting, coronary artery bypass grafting and aspirin therapy), immunosuppressant therapy for psoriatic arthritis, renal failure and significant hypertension (189/109 $\mathrm{mmHg})$, severe untreated autoimmune urticaria, excessive alcohol consumption ( $>20 \mathrm{~g} /$ day for a female participant) with paroxysmal atrial fibrillation.

\subsection{Baseline and Follow-Up Studies}

Protocols applied during the baseline and follow-up studies were almost identical, as detailed below.

\subsubsection{Screening Visit}

Participants were invited to the Clinical Research Facility to a screening visit in the morning after an overnight fast. The study included physical examination, weight, height, waist and hip circumference and blood pressure (Omron, Model IA1B, Port Melbourne, Australia) measurements. Fasting blood samples were collected. Physical activity was assessed using the Stanford 7-day activity questionnaires, as described previously [18]. 


\subsubsection{Detailed Phenotyping}

On a separate day, participants underwent hyperinsulinaemic-euglycaemic clamp and dual-energy X-ray absorptiometry (DXA) to assess insulin resistance and body composition, respectively. Liver fat was assessed by computed tomography (CT) at baseline and, to minimise cumulative radiation exposure, proton magnetic resonance spectroscopy $\left({ }^{1} \mathrm{H}-\mathrm{MRS}\right)$ at follow-up, as detailed below. These are available for the entire baseline cohort $(n=99)$ and for a sub-cohort of the follow-up cohort $(n=41$, Figure 1).

Participants were instructed to abstain from physical activity and alcohol for 2 days prior to the study day and to arrive to the Clinical Research Facility after an overnight fast. Hyperinsulinaemic-euglycaemic clamp was performed using the same protocols used at the baseline studies [16,17]. Intravenous access was obtained by cannulating each arm at the ante-cubital fossa. One arm was used for obtaining venous blood glucose for monitoring throughout the clamp. The contralateral arm was used for insulin (Actrapid, Novo Nordisk Pharmaceuticals, Baulkham Hills, NSW, Australia) and 25\% glucose (Baxter Healthcare, Toongabbie, NSW, Australia) infusion. Insulin was infused at a constant rate, with a supra-physiological concentration chosen to suppress hepatic gluconeogenesis, so that differences in net glucose disposal between groups could be interpreted as differences in peripheral (mainly muscle) glucose disposal. Insulin infusion rate was the same as that used in the baseline studies, 60 [16] or 80 [17] $\mathrm{mU} / \mathrm{m}^{2} / \mathrm{min}$. Glucose was infused at a variable rate to maintain a venous glucose concentration of $4.5-5.5 \mathrm{mmol} / \mathrm{L}$. Insulin resistance (median clamp $\mathrm{M}$-value (M/I)) was expressed in terms of average glucose infusion rate (GIR) obtained from the last 30 min of the clamp (steady state) normalised to fat-free mass (FFM) and steady state serum insulin concentrations (I).

DXA (Lunar Prodigy, GE Healthcare, Chicago, IL, USA) was used to measure total body fat mass and FFM (enCORE software Version 16), the android and gynoid region, and visceral fat (CoreScan software, GE Healthcare) at St Vincent's Clinic Bone Densitometry (Sydney, Australia). Standard fields of view automatically placed by the DXA software included the android (abdominal) and gynoid (hip) regions. The lower margin of the android region was defined by the pelvic cut line and the lateral margins by the arm cut lines. The upper margin was set at a height that is equal to $20 \%$ of the distance between the pelvic cut line and the neck cut line. The height of the android region is used to delineate the gynoid area. The upper border is set below the pelvic cut at a distance that is 1.5 times the height of the android region. The height of the gynoid region is twice the height of the android region. The lateral borders are defined by the outer leg cut lines (GE Healthcare Lunar enCORE-based X-ray Bone Densitometer User Manual, 2013). Visceral adipose tissue was determined from the android region by the software algorithm, which corrects total fat mass in the android region for estimated subcutaneous fat, providing visceral adipose tissue volume in $\mathrm{cm}^{3}$ (which may be converted to mass using the multiplicative constant $0.94 \mathrm{~g} / \mathrm{cm}^{3}$ ).

Liver fat was measured by liver density, an inverse measure of fat content, derived from CT (Gemini GXL, Philips, The Netherlands) during the baseline study. Briefly, liver attenuation values (measured in Hounsfield units [Hu]) from a $10 \mathrm{~mm}$ axial slice at T12/L1 level were derived. Three regions of interest were measured and averaged (one in the left lobe, two in the right lobe) to calculate the liver attenuation value. ${ }^{1} \mathrm{H}-\mathrm{MRS}$ was performed at the follow-up studies, using a 1.5-Tesla Ingenia whole-body system (Philips Medical Systems, Best, The Netherlands). Briefly, image-guided, localised ${ }^{1} \mathrm{H}$-MRS were acquired from a voxel of $3.0 \times 3.0 \times 3.0 \mathrm{~cm}$, with volumes of interest centred within the right lobe of the liver. Subjects lay supine, with spectra acquired using the PRESS (point resolved spectroscopy) technique (TR $=2800 \mathrm{~ms}, \mathrm{TE}=36 \mathrm{~ms}$, six measurements, 1024 sample points) during respiratory gating. Spectral data were post-processed by magnetic resonance user interface software (jMRUI version 3.0, EU Project) as described [19]. In order to compare the liver fat content gathered in the baseline and follow-up studies using different imaging methods (CT and MRS, respectively), we considered the imaging modalities' correlations with the gold-standard method for defining fatty liver, the histological grading of liver tissue. Normal liver fat content is most commonly defined as 
macroscopic steatosis in less than 5\% of hepatocytes [20]. To define fatty liver, we applied cut-offs derived in the study by Van Werven et al., comparing CT, ${ }^{1} \mathrm{H}-\mathrm{MRS}$ and liver histology in a similar cohort. In that study of 46 men and women (average body mass index (BMI) $27 \mathrm{~kg} / \mathrm{m}^{2}, 59$ years of age) fatty liver ( $>5 \%$ liver fat by histology) correlated to a CT measure of $54.2 \mathrm{Hu}$ (with $74 \%$ sensitivity and $70 \%$ specificity) and ${ }^{1} \mathrm{H}-\mathrm{MRS}$ measure of $1.8 \%$ (with $91 \%$ sensitivity and $87 \%$ specificity) [21]. Hence, the presence of excess liver fat accumulation was determined by a liver attenuation value of less than $54.2 \mathrm{Hu}$ at baseline and a liver fat content of greater than $1.8 \%$ at follow-up.

\subsection{Biochemical Analyses}

Whole blood glucose was analysed using a glucose analyser (YSI 2300 Stat Plus, YSI Incorporated Ohio USA, Yellow Springs, OH, USA), and serum insulin was measured using radioimmunoassay (Human Insulin-Specific RIA, Millipore, Burlington, MA, USA). Serum lipid profile was analysed by a spectrophotometric assay (Advia ${ }^{\circledR} 2400$ Chemistry System [Siemens Medical Solutions Diagnostics, Tarrytown, NY, USA]), with low-density lipoprotein (LDL) calculated using the Friedewald equation. Fibroblast growth factor (FGF)-19, FGF-21, total adiponectin, fatty acid-binding protein 4 (FABP4), lipocalin 2 and retinol-binding protein 4 (RBP4) were measured by ELISA (Antibody and Immunoassay service, University of Hong Kong), as previously described [22]. Serum lipid profile and the circulating adipokines were measured in serum samples, from the baseline and follow-up study stored at $-80^{\circ} \mathrm{C}$, after the completion of the follow-up study, whereas whole blood glucose was measured in fresh samples when collected, on the baseline and follow-up studies. Serum insulin concentrations were measured in samples batched and stored at $-80{ }^{\circ} \mathrm{C}$ until analysis, at the end of the baseline and follow-up studies, separately.

\subsection{Statistical Analysis}

Groupings of the cohort were made using the BMI and M/I value from the baseline data. The Lean group included all individuals with $\mathrm{BMI}<25 \mathrm{~kg} / \mathrm{m}^{2}$. Those with BMI $\geq 25 \mathrm{~kg} / \mathrm{m}^{2}$ were categorised as $\mathrm{Ob}_{\text {Res }}$ if their M/I were below the median M/I value for each gender and $\mathrm{Ob}_{\text {Sen }}$ if above.

The baseline and follow-up data were analysed to check for homoscedasticity using a Bartlett test [23]. To compare the differences in outcome measures between groups, if the variances across the groups were equal, one-way ANOVA was performed followed by a Tukey-Kramer posthoc test for significance. In the case of unequal variances, Welsh's ANOVA was calculated and the Games-Howell posthoc test [24] used to determine significant differences. In both cases, the significance cutoff was 0.05 .

To analyse the changes in the variables as a function of time, the rate of change was determined as $\frac{\text { Follow-up Value - Baseline Value }}{\text { Time between measurements }}$ for each baseline group. To assess whether the variables for each group changed significantly over time, the values of the changes were tested to see if they were significantly different from zero. A one-sample $t$-test was performed both for all the data ( $\left.p_{\text {time }}\right)$ and for each group. The significance level in the latter case was corrected for multiple comparisons using a Bonferroni correction (significance at $p \leq 0.0167$ ), where the significance cutoff of 0.05 was divided by 3 , the number of groups. As the change with time data had unequal variances across the groups, Welsh's ANOVA with the Games-Howell posthoc test was used to determine significant differences between the groups ( $\left.p_{\text {group }}\right)$. A Chi-squared test was performed to test the change in liver fat status in the different groups from baseline to follow-up.

Pairwise Spearman correlations between baseline and follow-up values were calculated. Both the correlations with $p \leq 0.05$ and $p \leq 0.01$, taking multiple comparisons into account, were determined. 
Statistical analyses were implemented in MATLAB (R2018b The Mathworks, Inc. 2018, Natick, MA, USA).

\section{Results}

\subsection{Baseline Characteristics}

The cohort characteristics are described in Table 1. Median age in this cohort was 49.8 years (interquartile range (IQR) 22.9, $(37.2,60.0))$. When retrospectively grouping the baseline cohort, $\mathrm{Ob}_{\mathrm{Sen}}$ were significantly younger than $\mathrm{Ob}_{\text {Res }}(p=0.001)$ and not different from the Lean group $(p=0.99)$. $\mathrm{BMI}$ in $\mathrm{Ob}_{\text {Res }}$ was marginally higher than $\mathrm{Ob}_{\text {Sen }}(p=0.056)$. Fat-free mass and fat mass were not significantly different between $\mathrm{Ob}_{\text {Sen }}$ and $\mathrm{Ob}_{\text {Res }}(p \geq 0.24)$. While fat content in the gynoid region was not different between the overweight/obese groups, fat content in the android region in $\mathrm{Ob}_{\text {sen }}$ was intermediate between Lean and $\mathrm{Ob}_{\text {Res, }}$, and a similar observation was noted for visceral adipose tissue volume (Table 1). Liver fat measured by $\mathrm{CT}$ attenuation index in $\mathrm{Ob}_{\text {Sen }}$ was intermediate between the higher level measured in $\mathrm{Ob}_{\text {Res }}$ and lower level measured in the Lean group (Table 1).

Blood pressure (systolic and diastolic) and fasting blood glucose measured in $\mathrm{Ob}_{\text {Sen }}$ were intermediate between that measured in Lean and $\mathrm{Ob}_{\text {Res }}$ (Table 1). Fasting serum triglycerides were significantly higher in both $\mathrm{Ob}_{\text {Sen }}$ and $\mathrm{Ob}_{\text {Res }}$ compared with Lean $(p \leq 0.002)$, while fasting HDL-cholesterol and LDL-cholesterol were not significantly different between the groups $(p \geq 0.15$, Table 1).

By design, baseline insulin sensitivity $\left(\mathrm{M} / \mathrm{I}\right.$ value) was higher in $\mathrm{Ob}_{\text {Sen }}$ compared with $\mathrm{Ob}_{\text {Res }}$. M/I was not different between Lean and $\mathrm{Ob}_{\mathrm{Sen}}$ and was significantly higher in Lean compared with $\mathrm{Ob}_{\text {Res }}$ (Figure 2A). Similarly, fasting insulin was significantly lower in $\mathrm{Ob}_{\text {Sen }}$ versus $\mathrm{Ob}_{\text {Res }}$, and not different between Lean and $\mathrm{Ob}_{\text {Sen }}$ (Figure 2B).

Circulating adiponectin was significantly higher and FABP4 lower in Lean compared with $\mathrm{Ob}_{\text {Res }}$ $(p \leq 0.026)$, and concentrations of these adipokines in $\mathrm{Ob}_{\text {Sen }}$ were not significantly different from either Lean or $\mathrm{Ob}_{\text {Res }}$. Other circulating cytokines, including FGF19, FGF21, lipocalin-2 and RBP4, were not significantly different between the groups ( $p \geq 0.23$, Table 1 ).

Self-reported physical activity engagement was not significantly different between the groups $(p=0.52$, data not shown). 
Table 1. Characteristics of the cohort at baseline and follow-up.

\begin{tabular}{|c|c|c|c|c|c|c|c|c|}
\hline \multirow[b]{2}{*}{ Characteristic } & \multicolumn{4}{|c|}{ Baseline } & \multicolumn{4}{|c|}{ Follow-Up } \\
\hline & Lean & $\mathrm{Ob}_{\text {Sen }}$ & $\mathrm{Ob}_{\text {Res }}$ & ANOVA $p$ Value & Lean & $\mathrm{Ob}_{\text {Sen }}$ & $\mathrm{Ob}_{\text {Res }}$ & ANOVA $p$ Value \\
\hline $\mathrm{N}(\mathrm{M} / \mathrm{F})$ & $42(20 / 22)$ & $30(15 / 15)$ & $27(12 / 15)$ & & $17(11 / 6)$ & $20(11 / 9)$ & $20(8 / 12)$ & \\
\hline Age (years) & $45.6 \pm 1.9^{\mathrm{c}}$ & $45.2 \pm 2.3^{c}$ & $57.7 \pm 2.4^{\mathrm{a}, \mathrm{b}}$ & $0.00^{1}$ & $54.6 \pm 2.7^{c}$ & $54.2 \pm 2.4^{\mathrm{c}}$ & $63.4 \pm 2.4^{\mathrm{a}, \mathrm{b}}$ & $0.01^{1}$ \\
\hline Weight $(\mathrm{kg})$ & $64.4 \pm 2.0^{b, c}$ & $85.1 \pm 2.3^{a}$ & $91.0 \pm 2.4^{\mathrm{a}}$ & $0.00^{1}$ & $64.4 \pm 3.4^{\mathrm{b}, \mathrm{c}}$ & $89.5 \pm 3.1^{\mathrm{a}}$ & $92.0 \pm 3.1^{\mathrm{a}}$ & $0.00^{1}$ \\
\hline BMI $\left(\mathrm{kg} / \mathrm{m}^{2}\right)$ & $22.2 \pm 0.6^{b, c}$ & $28.9 \pm 0.7^{a}$ & $32.0 \pm 0.7^{\mathrm{a}}$ & $0.00^{1}$ & $22.8 \pm 1.0^{\mathrm{b}, \mathrm{c}}$ & $29.9 \pm 0.9^{\text {a }}$ & $32.0 \pm 0.9^{\mathrm{a}}$ & $0.00^{1}$ \\
\hline Waist circumference $(\mathrm{cm})$ & $80 \pm 1^{b, c}$ & $99 \pm 2^{\mathrm{a}}$ & $106 \pm 2^{a}$ & $0.00^{1}$ & $83 \pm 3^{b, c}$ & $103 \pm 2^{\mathrm{a}}$ & $107 \pm 2^{\mathrm{a}}$ & $0.00^{1}$ \\
\hline Systolic blood pressure (mmHg) & $114 \pm 2^{b, c}$ & $121 \pm 2^{\mathrm{a}, \mathrm{c}}$ & $134 \pm 3^{a, b}$ & $0.00^{1}$ & $124 \pm 4^{c}$ & $127 \pm 4^{\mathrm{c}}$ & $143 \pm 4^{\mathrm{a}, \mathrm{b}}$ & $0.00^{1}$ \\
\hline Diastolic blood pressure $(\mathrm{mmHg})$ & $71 \pm 1^{b, c}$ & $76 \pm 1^{a, c}$ & $86 \pm 2^{a, b}$ & $0.00^{1}$ & $79 \pm 3^{c}$ & $80 \pm 3^{c}$ & $91 \pm 3^{\mathrm{a}, \mathrm{b}}$ & $0.00^{1}$ \\
\hline Fasting blood glucose $(\mathrm{mmol} / \mathrm{L})$ & $4.5 \pm 0.1^{b, c}$ & $4.7 \pm 0.1^{\mathrm{a}, \mathrm{c}}$ & $5.1 \pm 0.1 \mathrm{a}, \mathrm{b}$ & $0.00^{1}$ & $4.5 \pm 0.1^{\mathrm{c}}$ & $4.8 \pm 0.1$ & $5.1 \pm 0.1^{\mathrm{a}}$ & $0.00^{1}$ \\
\hline Total body fat mass (\%) & $29 \pm 1^{b, c}$ & $38 \pm 1^{\mathrm{a}}$ & $41 \pm 1^{\mathrm{a}}$ & $0.00^{1}$ & $31 \pm 2^{c}$ & $40 \pm 2$ & $42 \pm 2^{\mathrm{a}}$ & $0.00^{1}$ \\
\hline Android fat mass ( $\%$ of total android mass) & $26 \pm 1^{b, c}$ & $42 \pm 1^{a, c}$ & $47 \pm 1$ & $0.00^{1}$ & $29 \pm 3^{b, c}$ & $45 \pm 3^{a}$ & $48 \pm 2^{\mathrm{a}}$ & $0.00^{1}$ \\
\hline Gynoid fat mass ( $\%$ of total gynoid mass) & $33 \pm 1^{b, c}$ & $39 \pm 2^{\mathrm{a}}$ & $41 \pm 2$ & $0.00^{1}$ & $34 \pm 3^{c}$ & $41 \pm 3$ & $42 \pm 2^{\mathrm{a}}$ & $0.02^{1}$ \\
\hline Visceral adipose tissue $\left(\mathrm{cm}^{3}\right)$ & $358 \pm 110^{b, c}$ & $1123 \pm 129 \mathrm{a}, \mathrm{c}$ & $1962 \pm 13^{a, b}$ & $0.00^{1}$ & $593 \pm 293^{c}$ & $1289 \pm 307^{c}$ & $2370 \pm 229 \mathrm{a}, \mathrm{b}$ & $0.00^{1}$ \\
\hline Liver fat *\# & $60 \pm 2^{b, c}$ & $56 \pm 2^{a, c}$ & $43 \pm 2^{a, b}$ & $0.00^{1}$ & $1.4 \pm 2.2^{\mathrm{c}}$ & $4.2 \pm 2.3$ & $8.6 \pm 1.8^{\mathrm{a}}$ & $0.00^{1}$ \\
\hline Total cholesterol $(\mathrm{mmol} / \mathrm{L})^{2}$ & $4.3 \pm 0.2$ & $4.8 \pm 0.2$ & $4.7 \pm 0.2$ & 0.04 & $5.1 \pm 0.3$ & $5.1 \pm 0.3$ & $4.6 \pm 0.2$ & 0.30 \\
\hline Triglycerides $(\mathrm{mmol} / \mathrm{L})^{2}$ & $0.9 \pm 0.1 \mathrm{~b}, \mathrm{c}$ & $1.3 \pm 0.1^{\mathrm{a}}$ & $1.9 \pm 0.2^{\mathrm{a}}$ & $0.00^{1}$ & $1.1 \pm 0.2^{\mathrm{c}}$ & $1.3 \pm 0.2$ & $1.8 \pm 0.1^{\mathrm{a}}$ & $0.00^{1}$ \\
\hline HDL-cholesterol $(\mathrm{mmol} / \mathrm{L})^{2}$ & $1.3 \pm 0.1$ & $1.3 \pm 0.1$ & $1.2 \pm 0.1$ & 0.63 & $1.6 \pm 0.1^{\mathrm{c}}$ & $1.4 \pm 0.1^{\mathrm{c}}$ & $1.2 \pm 0.1^{\mathrm{a}, \mathrm{b}}$ & $0.00^{1}$ \\
\hline LDL-cholesterol $(\mathrm{mmol} / \mathrm{L})^{2}$ & $2.6 \pm 0.1$ & $2.9 \pm 0.2$ & $2.7 \pm 0.2$ & 0.15 & $3.0 \pm 0.2$ & $3.1 \pm 0.2$ & $2.6 \pm 0.2$ & 0.34 \\
\hline Adiponectin (mg/L) & $28.6 \pm 3.1^{c}$ & $23.8 \pm 2.9$ & $17.4 \pm 2.9^{\mathrm{a}}$ & $0.01^{1}$ & $27.7 \pm 2.8$ & $23.8 \pm 2.7$ & $18.7 \pm 2.6$ & 0.07 \\
\hline FABP4 $(\mu \mathrm{g} / \mathrm{L})$ & $12.5 \pm 5.5^{c}$ & $18.7 \pm 5.0$ & $34.1 \pm 4.9^{\mathrm{a}}$ & $0.01^{1}$ & $13.9 \pm 6.6$ & $17.0 \pm 6.0$ & $32.2 \pm 5.7$ & 0.08 \\
\hline FGF19 (ng/L) & $149 \pm 37$ & $107 \pm 33$ & $131 \pm 32$ & 0.70 & $102 \pm 26$ & $110 \pm 26$ & $112 \pm 24$ & 0.96 \\
\hline FGF21 (ng/L) & $156 \pm 53$ & $143 \pm 46$ & $240 \pm 40$ & 0.23 & $151 \pm 45$ & $176 \pm 35$ & $191 \pm 32$ & 0.77 \\
\hline Lipocalin-2 ( $\mu \mathrm{g} / \mathrm{L})$ & $104 \pm 11$ & $93 \pm 10$ & $83 \pm 10$ & 0.37 & $114 \pm 23$ & $82 \pm 22$ & $79 \pm 21$ & 0.48 \\
\hline RBP4 (mg/L) & $3.0 \pm 0.5$ & $2.3 \pm 0.5$ & $2.5 \pm 0.5$ & 0.60 & $2.8 \pm 0.4$ & $2.6 \pm 0.4$ & $2.1 \pm 0.4$ & 0.38 \\
\hline Participants treated with anti-hypertensive medication (n) & 1 & 2 & 8 & & 1 & 0 & 4 & \\
\hline Participants treated with lipid lowering medication (n) & 0 & 3 & 7 & & 1 & 3 & 6 & \\
\hline
\end{tabular}

Participants treated with lipid lowering medication (n)

Data are mean \pm standard error of the mean (SEM). Significance was tested using one-way Analysis of Variance (significant values highlighted in bold) with Games-Howell post hoc

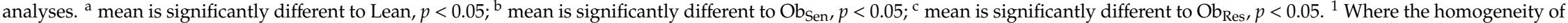
variances assumption was violated, the Welch statistic was used with Games-Howell post hoc. * Baseline based on CT attenuation (Hu) and follow-up based on ${ }^{1} \mathrm{H}-\mathrm{MRS}$ (\%). ${ }^{\#}$ Liver attenuation by CT is an inverse correlate of liver fat content. ${ }^{2}$ Data logged prior to statistical analyses. Abbreviations: FGF, fibroblast growth factor; FABP4, fatty-acid binding protein 4; RBP4, retinol-binding protein 4 . 
A

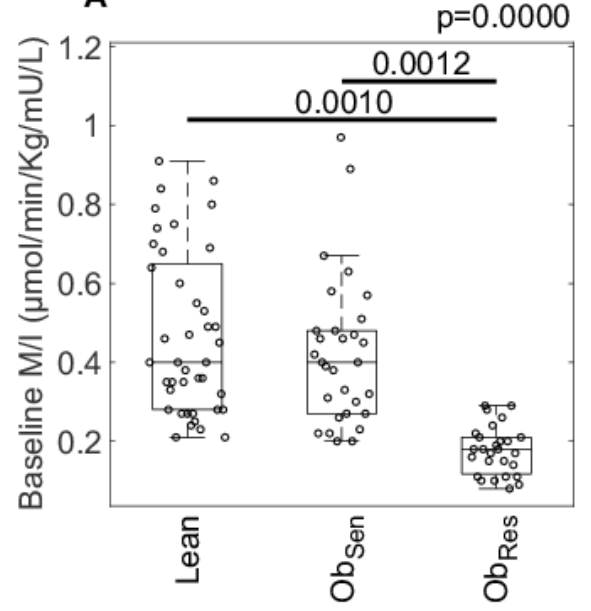

C

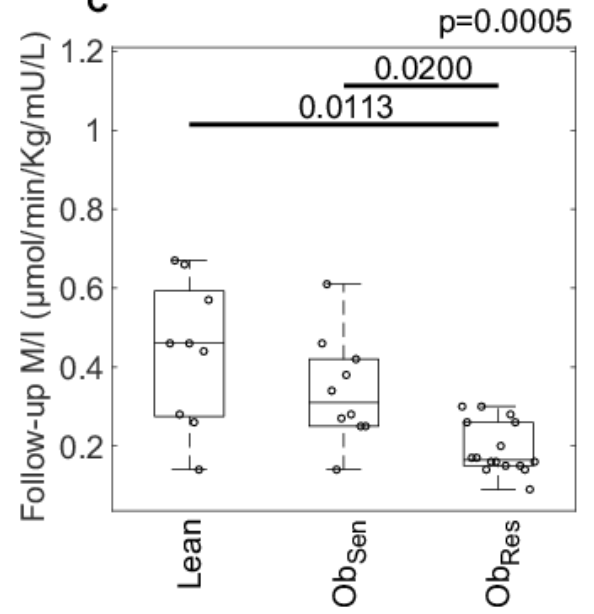

B

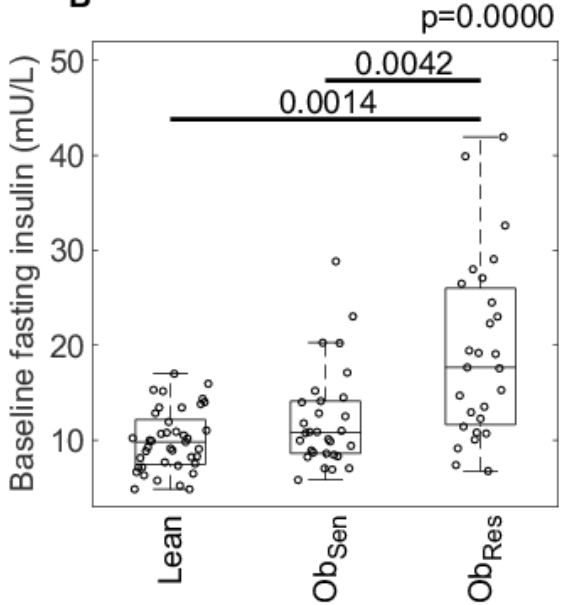

D

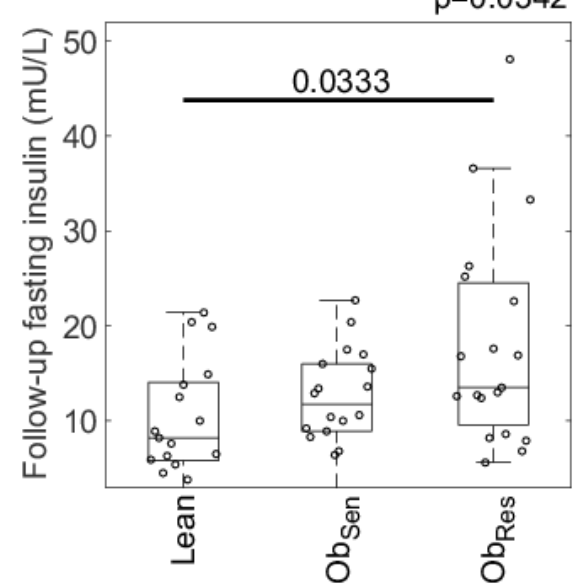

Figure 2. Insulin resistance at baseline and follow-up in Lean and overweight/obese insulin-resistant $\left(\mathrm{Ob}_{\text {Res }}\right)$ and insulin-sensitive $\left(\mathrm{Ob}_{\mathrm{Sen}}\right)$ individuals. Insulin resistance (median clamp M-value $(\mathrm{M} / \mathrm{I})$, A and C) and fasting serum insulin (B and D) measured at baseline and follow-up, respectively, in Lean and overweight/obese individuals. Data are individual data points with median and interquartile range (IQR). Welsh's ANOVA was calculated and the Games-Howell posthoc test was used to determine significant differences. The $p$ for the Welsh's ANOVA is indicated at the top of the plots, with the significance between groups indicated.

\subsection{Follow-Up}

Average follow-up was $5.4 \pm 0.1$ years (range 4.3-7.6). Of 99 participants at baseline, 57 participated in the follow-up study (Figure 1). On average, individuals lost to follow-up (for all reasons as detailed in Figure 1, $n=42$ ) were younger, significantly leaner and metabolically healthier at baseline, with lower blood pressure and a more favorable baseline lipid profile (Table 2).

BMI remained statistically indistinguishable between $\mathrm{Ob}_{\text {Res }}$ and $\mathrm{Ob}_{\text {Sen }}$ at follow-up $(p=0.33$, Table 1), but, similarly to baseline, visceral fat volume remained lower in $\mathrm{Ob}_{\text {Sen }}$ compared with $\mathrm{Ob}_{\text {Res }}$ $\left(p=0.03\right.$, Table 1). At follow-up, however, the distinction in liver fat content, measured by ${ }^{1} \mathrm{H}-\mathrm{MRS}$, between $\mathrm{Ob}_{\text {Sen }}$ and the $\mathrm{Ob}_{\text {Res }}$ group was no longer significant ( $p=0.31$, Table 1 ). 
Table 2. Baseline characteristics of participants who were lost to follow-up versus those who were studied.

\begin{tabular}{|c|c|c|c|}
\hline Baseline Characteristic & Not Studied & Studied & $p$ Value \\
\hline $\mathrm{N}(\mathrm{M} / \mathrm{F})$ & $42(20 / 22)$ & $57(27 / 30)$ & $0.00^{1}$ \\
\hline Age (years) & $44.4 \pm 2.0$ & $52.1 \pm 1.7$ & $0.00^{1}$ \\
\hline $\operatorname{BMI}\left(\mathrm{kg} / \mathrm{m}^{2}\right)$ & $25.2 \pm 0.8$ & $28.1 \pm 0.7$ & $0.00^{1}$ \\
\hline Waist circumference (cm) & $88 \pm 2$ & $96 \pm 2$ & $0.00^{1}$ \\
\hline Systolic blood pressure (mmHg) & $117 \pm 2$ & $125 \pm 2$ & $0.01^{1}$ \\
\hline Diastolic blood pressure (mmHg) & $75 \pm 2$ & $78 \pm 1$ & $0.04^{1}$ \\
\hline Fasting blood glucose (mmol/L) & $4.5 \pm 0.1$ & $4.8 \pm 0.1$ & $0.00^{1}$ \\
\hline Fasting insulin (mU/L) & $11.7 \pm 1.1$ & $14.4 \pm 0.9$ & $0.03^{1}$ \\
\hline Total cholesterol $(\mathrm{mmol} / \mathrm{L})^{2}$ & $4.1 \pm 0.2$ & $4.9 \pm 0.1$ & $0.00^{1}$ \\
\hline Triglycerides $(\mathrm{mmol} / \mathrm{L})^{2}$ & $1.1 \pm 0.1$ & $1.5 \pm 0.1$ & $0.01^{1}$ \\
\hline HDL-cholesterol $(\mathrm{mmol} / \mathrm{L})^{2}$ & $1.1 \pm 0.1$ & $1.4 \pm 0.0$ & $0.00^{1}$ \\
\hline LDL-cholesterol $(\mathrm{mmol} / \mathrm{L})^{2}$ & $2.5 \pm 0.1$ & $2.9 \pm 0.1$ & $0.02^{1}$ \\
\hline
\end{tabular}

Data are mean \pm SEM. ${ }^{1}$ Where the homogeneity of variances assumption was violated, the Welch statistic was used. Significance was tested using one-way Analysis of Variance (significant values highlighted in bold). ${ }^{2}$ Data logged prior to statistical analyses. Abbreviations: HDL: high-density lipoprotein, LDL: low-density lipoprotein.

Between-group analysis at the follow-up time point revealed that $\mathrm{M} / \mathrm{I}$ at follow-up in $\mathrm{Ob}_{\mathrm{Sen}}$ remained significantly higher compared to $\mathrm{Ob}_{\mathrm{Res}}$, and not different from Lean (Figure 2C). Fasting insulin was not significantly different between $\mathrm{Ob}_{S e n}$ and $\mathrm{Ob}_{\text {Res }}$ at follow-up $(p=0.13)$, but remained lower in Lean compared with $\mathrm{Ob}_{\text {Res }}$ (Figure 2D).

Systolic and diastolic blood pressure remained significantly lower in $\mathrm{Ob}_{\mathrm{Sen}}$ and Lean compared with $\mathrm{Ob}_{\mathrm{Res}}(p \leq 0.012)$, but fasting blood glucose was not significantly different between $\mathrm{Ob}_{\text {Res }}$ and $\mathrm{Ob}_{\text {Sen }}$ $(p=0.37)$, only significantly lower in Lean versus $\operatorname{Ob}_{\text {Res }}(p=0.004)$. HDL-cholesterol was significantly higher in $\mathrm{Ob}_{\text {Sen }}$ compared with $\mathrm{Ob}_{\text {Res }}(p=0.010)$, and serum triglycerides were significantly lower in Lean compared with $\mathrm{Ob}_{\text {Res }}(p=0.003)$, but not different between $\mathrm{Ob}_{\text {Sen }}$ and either Lean or $\mathrm{Ob}_{\text {Res }}$ $(p=0.070$, Table 1$)$.

Similarly to baseline, self-reported physical activity engagement was not different between the groups at the follow-up time point ( $p=0.35$, data not shown).

\subsection{Change in Anthropometry, Metabolic Health and Insulin Resistance}

We evaluated the change in metabolic parameters with time, by calculating the difference in the values of the measures from baseline to follow-up, normalising for the time elapsed between the baseline and follow-up studies.

\subsubsection{Body Weight and Fat Content}

Surprisingly, BMI ( $p_{\text {time }}=0.24$, Figure $\left.3 \mathrm{~A}\right)$ and waist circumference $\left(p_{\text {time }}=0.17\right.$, Figure $\left.3 \mathrm{~B}\right)$ did not change significantly over time in this cohort. However, body fat increased significantly over time ( $p_{\text {time }}=0.006$, Figure 3 C). Other anthropometric and body composition (DXA-derived) variables changed significantly over time, and while none showed a significant difference between groups (Figure 3), in many the significant changes over time were driven by the $\mathrm{Ob}_{\text {Res }}$ group (as evaluated by one-way $t$-test, Bonferroni-corrected and accepting $p \leq 0.0167$ as statistically significant). For example, FFM decreased significantly $\left(p_{\text {time }}=0.0035\right.$, Figure 3D), and the change with time primarily driven by the $\mathrm{Ob}_{\text {Res }}(p=0.0163)$. Similarly, fat content in the android region increased significantly over time $\left(p_{\text {time }}=0.0013\right.$, Figure $\left.3 \mathrm{E}\right)$, driven by the $\mathrm{Ob}_{\text {Res }}$ group $(p=0.0087$, Figure $3 \mathrm{E})$. Visceral fat volume increased over time $\left(p_{\text {time }}<0.001\right.$, Figure $\left.3 \mathrm{~F}\right)$, driven by a significant increase in the $\mathrm{Ob}_{\text {Res }}(p=0.0001$, 
Figure 3F). On the other hand, gynoid region mass decreased significantly in the cohort $\left(p_{\text {time }}<0.001\right)$, also driven by a decrease in the $\mathrm{Ob}_{\text {Res }}(p=0.0005)$.

\subsubsection{Liver Fat}

Fatty liver status did not change significantly for any of the groups from baseline to follow-up (Chi-squared test $p=0.62, p=0.32$ and $p=1$, for Lean, $\mathrm{Ob}_{\text {Sen }}$ and $\mathrm{Ob}_{\text {Res }}$, respectively). There was a larger proportion of $\mathrm{Ob}_{\mathrm{Sen}}$ compared with $\mathrm{Ob}_{\mathrm{Res}}$ having a stable absence of fatty liver (56 versus $12 \%$ ); and a larger proportion of $\mathrm{Ob}_{\text {Res }}$ compared with $\mathrm{Ob}_{\text {Sen }}$ having a stable presence of fatty liver (76 versus $22 \%$, Table 3).

Table 3. Presence of fatty liver at baseline and follow-up in Lean, $\mathrm{Ob}_{\mathrm{Sen}}$ and $\mathrm{Ob}_{\mathrm{Res}}$.

\begin{tabular}{cccc}
\hline Presence of Fatty Liver & \multicolumn{3}{c}{ Study Group } \\
\cline { 2 - 4 } (Baseline to Follow-Up) & $\begin{array}{c}\text { Lean } \\
(n, \% \text { of Group) }\end{array}$ & $\begin{array}{c}\text { Ob }_{\text {Sen }} \\
(n, \% \text { of Group) }\end{array}$ & $\begin{array}{c}\text { Ob }_{\text {Res }} \\
(n, \% \text { of Group) }\end{array}$ \\
\hline Stable Absence $(n=14)$ & $7(64 \%)$ & $5(56 \%)$ & $2(12 \%)$ \\
\hline Gain of fatty liver $(n=5)$ & $2(18 \%)$ & $2(22 \%)$ & $1(6 \%)$ \\
\hline Loss of fatty liver $(n=2)$ & $1(9 \%)$ & $0(0 \%)$ & $1(6 \%)$ \\
\hline Stable Presence $(n=16)$ & $1(9 \%)$ & $2(22 \%)$ & $13(76 \%)$ \\
\hline Total $(n=37)$ & $11(100 \%)$ & $9(100 \%)$ & $17(100 \%)$ \\
\hline
\end{tabular}

Paired liver fat measurements were available for a sub-cohort of 37 individuals who had CT and MRS at baseline and follow-up, respectively. * Presence of fatty liver determined by a CT value of $<54.2 \mathrm{Hu}$ at baseline and MRS $>1.8 \%$ at follow-up, as described by van Werven et al. [21]. Terminology: Stable Absence: Fatty liver absent at baseline and follow-up; Gain of fatty liver: Fatty liver absent at baseline but present at follow-up; Loss of fatty liver: Fatty liver present at baseline but absent at follow-up; Stable Presence: Fatty liver present at baseline and follow-up.
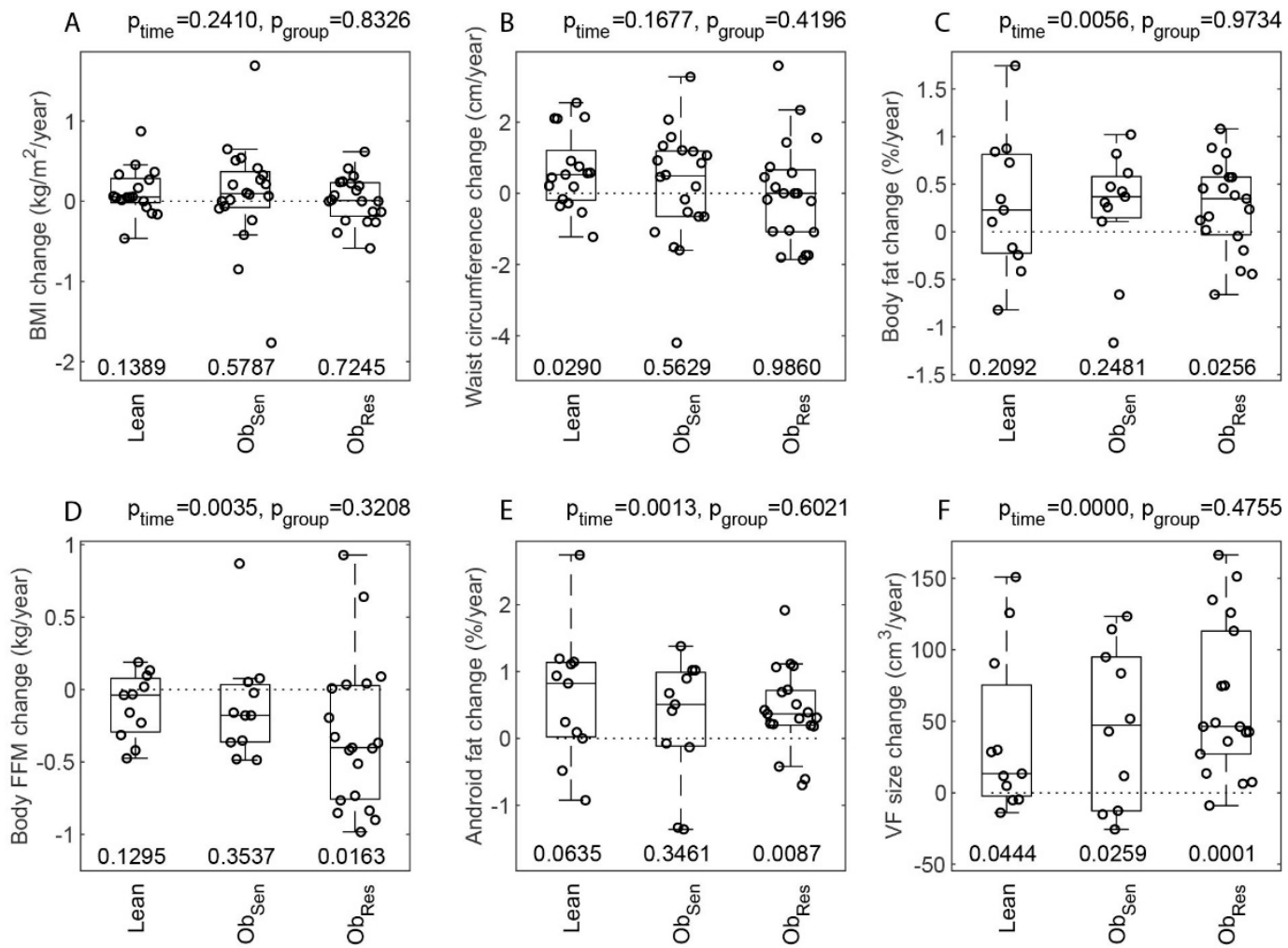

Figure 3. Cont. 

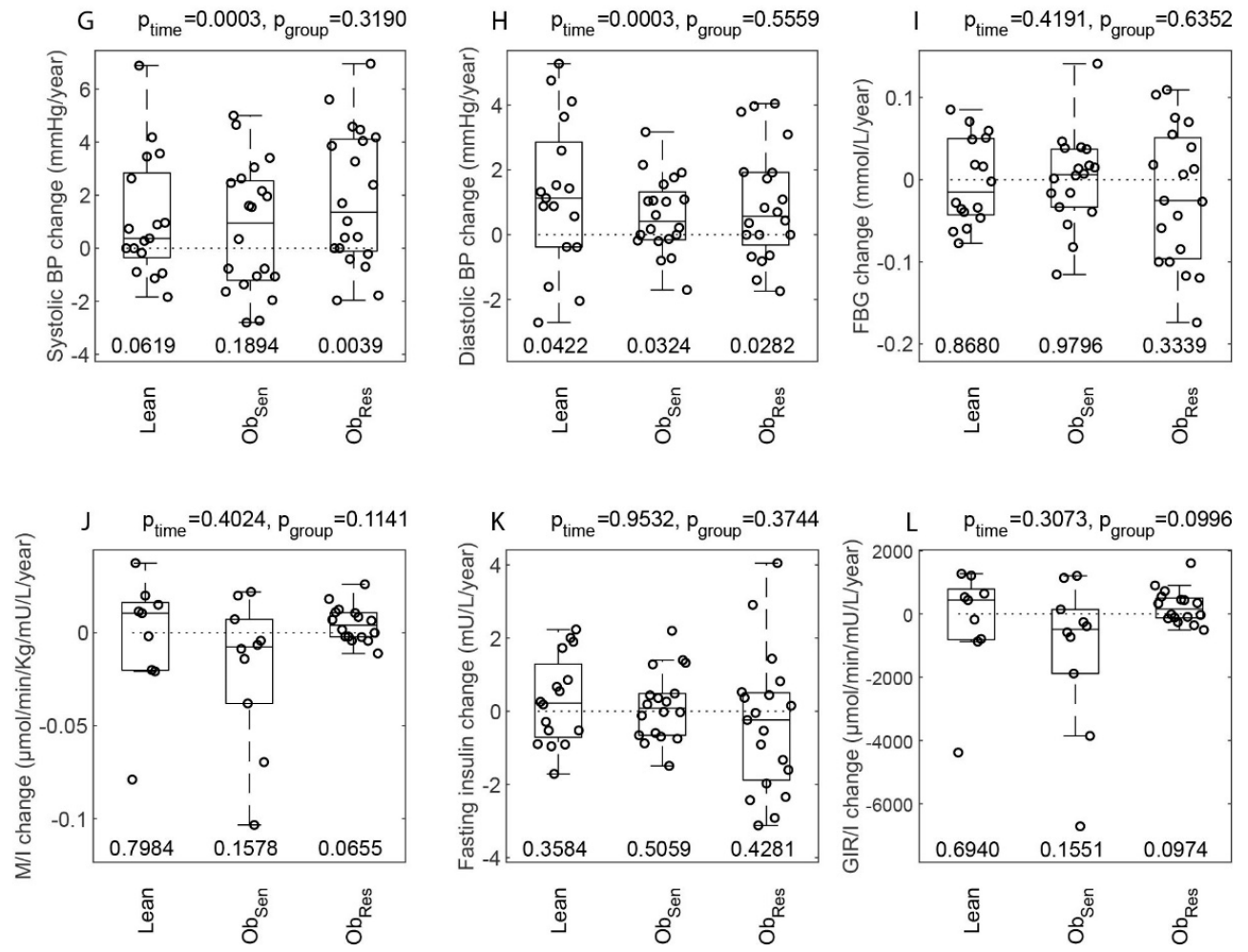

Figure 3. Change in anthropometry, metabolic health and glucose regulation markers from baseline to follow-up in Lean and overweight/obese insulin-resistant and insulin-sensitive individuals. Annual change in body mass index (BMI) (A), waist circumference (B), body fat (C), fat-free mass (D), android fat (E), visceral fat (F), systolic (G) and diastolic (H) blood pressure, fasting blood glucose (I), M/I (J), fasting insulin (K) and glucose infusion rate (GIR)/I (L) in Lean and overweight/obese individuals. Change (IQR) in variables as a function of time, for each of the baseline groups: Lean, $\mathrm{Ob}_{\text {Res }}$ and $\mathrm{Ob}_{\text {Sen }}$. The change was determined as $\frac{\text { Follow-up Value-Baseline Value }}{\text { Time between measurements }}$. Differences between the groups were assessed using a Welsh's ANOVA (accounting for unequal variances in the change data) with the Games-Howell posthoc test. The pgroup value is indicated at the top of each plot for each variable. Changes over time for the cohort were assessed using a one-sample $t$-test for difference from zero with $p_{\text {time }}$ also indicated at the top of each plot. The $p$ values for the differences from zero for each individual group are shown at the bottom of each plot. A correction for multiple comparisons (Bonferroni) was applied with significance set at $p \leq 0.0167$. Data are individual values of change (IQR). Abbreviations: WC, waist circumference; FFM, fat-free mass; SBP, systolic blood pressure; DBP, diastolic blood pressure; FBG, fasting blood glucose.

\subsubsection{Cardiovascular Health Markers and Insulin Resistance}

Systolic blood pressure increased overall ( $p_{\text {time }}=0.0003$, Figure 3G), and significantly in $\mathrm{Ob}_{\text {Res }}$ $(p=0.0039)$, while diastolic blood pressure, whilst increasing across the whole cohort $\left(p_{\text {time }}=0.0003\right)$, did not change significantly (with Bonferroni correction) within any of the groups (Figure $3 \mathrm{H}$ ). Fasting glucose $\left(p_{\text {time }}=0.42\right.$, Figure 3I), HDL-cholesterol $\left(p_{\text {time }}=0.88\right)$, LDL-cholesterol $\left(p_{\text {time }}=0.75\right)$, triglycerides $\left(p_{\text {time }}=0.73\right)$ and total cholesterol $\left(p_{\text {time }}=0.78\right)$ did not change significantly over time in this cohort (with little change in the number of individuals treated with lipid-lowering medication, Table 1). Similarly, $\mathrm{M} / \mathrm{I}\left(p_{\text {time }}=0.40\right.$, Figure $\left.3 \mathrm{~J}\right)$ and fasting insulin $\left(p_{\text {time }}=0.95\right.$, Figure $\left.3 \mathrm{~K}\right)$ did not change significantly over time. As body FFM decreased significantly in $\mathrm{Ob}_{\text {Res }}$ (Figure $3 \mathrm{D}, p_{\mathrm{ObRes}}=0.0163$ ), we calculated a new variable GIR normalised to circulating steady state insulin, but not normalised to FFM. Similar to M/I, this new variable GIR/I did not change significantly over time in this cohort $\left(p_{\text {time }}=0.31\right.$, Figure $\left.3 \mathrm{~L}\right)$. 


\subsection{Correlates of Follow-Up Insulin Resistance}

Baseline and follow-up anthropometry, metabolic markers and glucose control, including insulin resistance, correlated tightly (Figure 4). The best correlate of follow-up insulin resistance (M/I) was baseline $\mathrm{M} / \mathrm{I}$, followed by inverse correlations with central adiposity, measured by visceral fat volume and waist circumference, fat-free mass, BMI, diastolic blood pressure, fasting serum insulin and liver fat (Table 4).

Table 4. Baseline correlates of follow-up insulin resistance (M/I).

\begin{tabular}{|c|c|c|}
\hline Baseline Measure & $\mathbf{R}$ & $p$ \\
\hline $\mathrm{M} / \mathrm{I}$ & 0.76 & $1.1 \times 10^{-07}$ \\
\hline Visceral fat volume & -0.63 & $5.7 \times 10^{-05}$ \\
\hline Waist circumference & -0.63 & $5.8 \times 10^{-05}$ \\
\hline Fat-free mass & -0.53 & 0.001 \\
\hline BMI & -0.52 & 0.001 \\
\hline Diastolic blood pressure & -0.49 & 0.003 \\
\hline Fasting Insulin & -0.50 & 0.003 \\
\hline Liver attenuation $(\mathrm{Hu}) *$ & 0.49 & 0.003 \\
\hline Systolic blood pressure & -0.47 & 0.004 \\
\hline Fat in the android region ( $\%$ of total abdominal fat) & -0.46 & 0.006 \\
\hline Serum triglycerides & -0.38 & 0.025 \\
\hline Serum HDL cholesterol & 0.36 & 0.034 \\
\hline Adiponectin & 0.34 & 0.044 \\
\hline Fasting blood glucose & -0.34 & 0.046 \\
\hline Age & -0.33 & 0.052 \\
\hline FGF21 & -0.29 & 0.126 \\
\hline FABP4 & -0.26 & 0.149 \\
\hline Body fat (\% whole body mass) & -0.25 & 0.154 \\
\hline Serum LDL & 0.24 & 0.163 \\
\hline Total Cholesterol & 0.19 & 0.277 \\
\hline RBP4 & 0.06 & 0.711 \\
\hline Fasting NEFA & 0.07 & 0.714 \\
\hline Lipocalin-2 & 0.05 & 0.764 \\
\hline FGF19 & -0.03 & 0.878 \\
\hline Fat in the gynoid region (\% of total abdominal fat) & -0.02 & 0.922 \\
\hline
\end{tabular}

Spearman coefficients were calculated. Significant $p$ values are bolded; ${ }^{*}$ Liver attenuation by CT is an inverse correlate of liver fat content. 


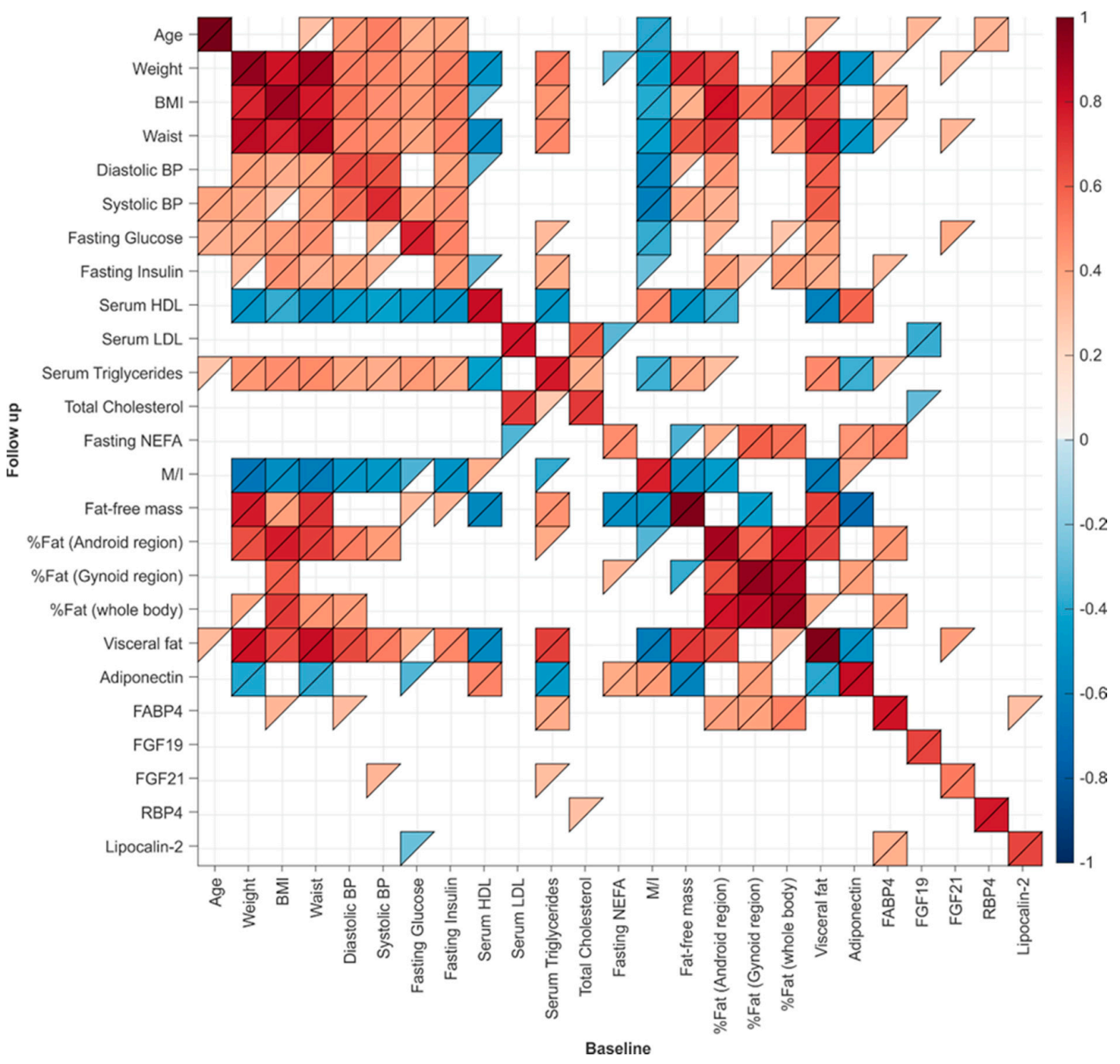

Figure 4. Associations between baseline and follow-up metabolic health, anthropometry and body composition. Pairwise Spearman coefficients were calculated and the $p$ values determined. If $0 \leq p<0.05$, then the $\mathrm{R}$ value of the correlation is shown in color, with upper triangle indicating $0 \leq p<0.05$, and lower triangle indicating $0 \leq p<0.01$ for the correlation. The correlation coefficient is indicated using the color scale.

\section{Discussion}

In this study, we followed the change in insulin resistance, metabolic health and body fat composition in individuals with overweight and obesity over a 4.3-7.6 year period. Insulin resistance did not change significantly over time in this cohort, and, similarly to the Lean group, $\mathrm{Ob}_{\text {Sen }}$ maintained their superior insulin sensitivity relative to $\mathrm{Ob}_{\text {Res }}$ at follow-up. However, it is important to note that when we retrospectively grouped individuals who were overweight and obese into insulin-sensitive and insulin-resistant sub-groups, the $\mathrm{Ob}_{\text {Sen }}$ group was significantly younger than the $\mathrm{Ob}_{\text {Res }}$ group. This is consistent with large cohort epidemiological studies, following the change in metabolic health in individuals who were overweight and obese, reporting that metabolically healthy obesity is rare in older individuals, and that the majority of individuals who are overweight and obese are likely to acquire the metabolic syndrome over time, at ages ranging from early 50 s to late 80 s [7-14].

Two consistent predictors of maintenance of metabolic health in obesity across previous large cohort longitudinal studies were younger age, and a more peripheral fat distribution $[9,15]$. In our study, we found that insulin-resistant individuals who were overweight/obese were more susceptible 
than the insulin-sensitive groups to adverse deposition of abdominal adiposity (android region and visceral fat) and loss of gynoid region and fat-free mass. This was despite no change in BMI or waist circumference over time. Insulin resistance in obesity is strongly associated with muscle mass loss in the elderly, termed "sarcopenic obesity" [25]. In a large cohort of non-obese and obese individuals, Lee and colleagues reported that the proportion of muscle mass (appendicular muscle) to body weight was significantly elevated in men with obesity who remained metabolically healthy over 4 years [26]. The same was found in men and women who were non-obese, but interestingly, not in women with obesity [26]. Skeletal muscle is the primary tissue determining whole body insulin resistance. Fat-free mass loss was observed only in the $\mathrm{Ob}_{\text {Res }}$ sub-cohort. To our surprise, this was not reciprocated with further deterioration in insulin resistance measured by either hyperinsulinemic-euglycemic clamp or fasting insulin. This may be explained by these methodologies' lowest detection limits, or by the fact that the FFM loss was not substantial enough to affect whole body insulin resistance.

We and others have suggested that a low degree of liver steatosis is a strong feature of insulin sensitivity in obesity [27]. Indeed, liver fat content measured by $\mathrm{CT}$ in $\mathrm{Ob}_{\mathrm{Sen}}$ in the present study was intermediate, higher compared with Lean and lower compared with $\mathrm{Ob}_{\mathrm{Res}}$, confirming previous observations $[2,28]$. Presence or absence of fatty liver over time in the present study did not change for the majority of participants, with more $\mathrm{Ob}_{\mathrm{Sen}}$ having a stable absence of fatty liver than $\mathrm{Ob}_{\text {Res }}$ and more $\mathrm{Ob}_{\text {Res }}$ having a stable presence of fatty liver than $\mathrm{Ob}_{\text {Sen }}$. At follow-up, the significant distinction in liver fat content between $\mathrm{Ob}_{\mathrm{Sen}}$ and the $\mathrm{Ob}_{\text {Res }}$ was lost. We speculate that this relates to the smaller sample size at follow-up, and possibly inadequate statistical power, or the relatively short-term follow-up. Healthy adipose tissue expansion and better capacity to upregulate lipogenesis in adipose tissue $[2,29,30]$ are thought to explain protection against lipid spill-over to the liver and the muscle in insulin-sensitive obesity. While these findings should be interpreted cautiously due to the different modalities used to evaluate liver fat at baseline and follow-up, the maintenance of the baseline liver fat status by the majority of participants is consistent with the lack of significant change in insulin resistance over time in the present study.

Interestingly, the best correlate of future insulin resistance was insulin resistance measured at baseline, suggesting that insulin resistance is an intrinsic characteristic. Other strong predictors were visceral fat, waist circumference, BMI and liver fat. Higher waist circumference [15] and visceral fat area [11] have been previously suggested to predict loss of metabolic health in obesity over time. Here, we complement these findings and maintain that ectopic deposition of fat in the liver at younger age predicts future insulin resistance.

The strengths of our study include the detailed phenotyping using gold-standard measurement of insulin resistance and body fat composition and distribution, and the paired design. A major limitation is the loss of participants to follow-up and the small sample size at follow-up. Furthermore, bias relating to populations likely to volunteer to studies may have affected the findings and may explain the failure to detect changes in body weight over time, contrary to expectations. Lastly, different modalities were used to measure liver fat at baseline and follow-up and the cut-offs used to define fatty liver status were adopted from a different study population, which may have influenced the findings.

\section{Conclusions}

Our findings suggest that insulin resistance at an older age strongly aligns with unfavourable abdominal fat distribution and liver fat measured at a younger age. Furthermore, insulin resistance at a young age predisposes to adverse metabolic outcomes and fat-free mass loss, suggesting that maintenance of body fat-free mass should be encouraged to promote healthy aging in obesity.

Author Contributions: Conceptualisation, D.S.-B. and J.R.G.; investigation, A.T., K.T.T., L.P., M.G., J.B., J.Z., and A.X.; formal analysis and Figures, A.C.F.C.; analysis of MRS data, N.A.J.; supervision of analysis of DXA data, N.P.; writing - original draft preparation, A.T. and D.S.-B.; writing-review and editing, all authors; funding acquisition, D.S.-B. and J.R.G. 
Funding: This study was funded by the Diabetes Australia Research Program and the Garvan Research Foundation. Alice Tang was awarded an Australian Postgraduate Award from UNSW to support her PhD study.

Acknowledgments: We would like to thank the nurses of the Clinical Research Facility, Renee Richens, Lynne Schofield and Ashley Douglas.

Conflicts of Interest: The authors declare no conflict of interest.

\section{References}

1. Obesity and Overweight. Available online: http://www.who.int/en/news-room/fact-sheets/detail/obesityand-overweight (accessed on 31 January 2019).

2. Samocha-Bonet, D.; Dixit, V.D.; Kahn, C.R.; Leibel, R.L.; Lin, X.; Nieuwdorp, M.; Pietiläinen, K.H.; Rabasa-Lhoret, R.; Roden, M.; Scherer, P.E.; et al. Metabolically healthy and unhealthy obese-The 2013 stock conference report. Obes. Rev. 2014, 15, 697-708. [CrossRef]

3. Rey-López, J.P.; de Rezende, L.F.; Pastor-Valero, M.; Tess, B.H. The prevalence of metabolically healthy obesity: A systematic review and critical evaluation of the definitions used. Obes. Rev. 2014, 15, 781-790. [CrossRef]

4. Bo, S.; Musso, G.; Gambino, R.; Villois, P.; Gentile, L.; Durazzo, M.; Cavallo-Perin, P.; Cassader, M. Prognostic implications for insulin-sensitive and insulin-resistant normal-weight and obese individuals from a population-based cohort. Am. J. Clin. Nutr. 2012, 96, 962-969. [CrossRef] [PubMed]

5. Kloting, N.; Fasshauer, M.; Dietrich, A.; Kovacs, P.; Schon, M.R.; Kern, M.; Stumvoll, M.; Bluher, M. Insulin-sensitive obesity. Am. J. Physiol. Endocrinol. Metab. 2010, 299, E506-E515. [CrossRef] [PubMed]

6. Kramer, C.K.; Zinman, B.; Retnakaran, R. Are metabolically healthy overweight and obesity benign conditions?: A systematic review and meta-analysis. Ann. Intern. Med. 2013, 159, 758-769. [PubMed]

7. Roos, V.; Elmståhl, S.; Ingelsson, E.; Sundström, J.; Ärnlöv, J.; Lind, L. Metabolic Syndrome Development During Aging with Special Reference to Obesity Without the Metabolic Syndrome. Metab. Syndr. Relat. Disord. 2017, 15, 36-43. [CrossRef] [PubMed]

8. Zheng, R.; Liu, C.; Wang, C.; Zhou, B.; Liu, Y.; Pan, F.; Zhang, R.; Zhu, Y. Natural Course of Metabolically Healthy Overweight/Obese Subjects and the Impact of Weight Change. Nutrients 2016, 8, 430.

9. Khan, U.I.; Wang, D.; Karvonen-Gutierrez, C.A.; Khalil, N.; Ylitalo, K.R.; Santoro, N. Progression from metabolically benign to at-risk obesity in perimenopausal women: A longitudinal analysis of Study of Women Across the Nation (SWAN). J. Clin. Endocrinol. Metab. 2014, 99, 2516-2525. [CrossRef] [PubMed]

10. Kabat, G.C.; Wu, W.Y.-Y.; Bea, J.W.; Chen, C.; Qi, L.; Stefanick, M.L.; Chlebowski, R.T.; Lane, D.S.; Wactawski-Wende, J.; Wassertheil-Smoller, S.; et al. Metabolic phenotypes of obesity: Frequency, correlates and change over time in a cohort of postmenopausal women. Int. J. Obes. 2017, 41, 170. [CrossRef] [PubMed]

11. Hwang, Y.-C.; Hayashi, T.; Fujimoto, W.Y.; Kahn, S.E.; Leonetti, D.L.; McNeely, M.J.; Boyko, E.J. Visceral abdominal fat accumulation predicts the conversion of metabolically healthy obese subjects to an unhealthy phenotype. Int. J. Obes. 2015, 39, 1365-1370. [CrossRef]

12. Hamer, M.; Bell, J.A.; Sabia, S.; Batty, G.D.; Kivimäki, M. Stability of metabolically healthy obesity over 8 years: The English Longitudinal Study of Ageing. Eur. J. Endocrinol. 2015, 173, 703-708. [CrossRef] [PubMed]

13. Eshtiaghi, R.; Keihani, S.; Hosseinpanah, F.; Barzin, M.; Azizi, F. Natural course of metabolically healthy abdominal obese adults after 10 years of follow-up: The Tehran Lipid and Glucose Study. Int. J. Obes. 2015, 39, 514-519. [CrossRef] [PubMed]

14. Bell, J.A.; Hamer, M.; Sabia, S.; Singh-Manoux, A.; Batty, G.D.; Kivimaki, M. The natural course of healthy obesity over 20 years. J. Am. Coll. Cardiol. 2015, 65, 101-102. [CrossRef]

15. Appleton, S.L.; Seaborn, C.J.; Visvanathan, R.; Hill, C.L.; Gill, T.K.; Taylor, A.W.; Adams, R.J. Diabetes and cardiovascular disease outcomes in the metabolically healthy obese phenotype: A cohort study. Diabetes Care 2013, 36, 2388-2394. [CrossRef]

16. Samocha-Bonet, D.; Campbell, L.V.V.; Viardot, A.; Freund, J.; Tam, C.S.S.; Greenfield, J.R.R.; Heilbronn, L.K.K. A family history of type 2 diabetes increases risk factors associated with overfeeding. Diabetologia 2010, 53, 1700-1708. [CrossRef] [PubMed]

17. Tonks, K.T.; Ng, Y.; Miller, S.; Coster, A.C.F.; Samocha-Bonet, D.; Iseli, T.J.; Xu, A.; Patrick, E.; Yang, J.Y.H.; Junutula, J.R.; et al. Impaired Akt phosphorylation in insulin-resistant human muscle is accompanied by selective and heterogeneous downstream defects. Diabetologia 2013, 56, 875-885. [CrossRef] 
18. Washburn, R.A.; Jacobsen, D.J.; Sonko, B.J.; Hill, J.O.; Donnelly, J.E. The validity of the Stanford Seven-Day Physical Activity Recall in young adults. Med. Sci. Sports Exerc. 2003, 35, 1374-1380. [CrossRef]

19. Keating, S.E.; Hackett, D.A.; Parker, H.M.; O'Connor, H.T.; Gerofi, J.A.; Sainsbury, A.; Baker, M.K.; Chuter, V.H.; Caterson, I.D.; George, J.; et al. Effect of aerobic exercise training dose on liver fat and visceral adiposity. J. Hepatol. 2015, 63, 174-182. [CrossRef]

20. Petäjä, E.; Yki-Järvinen, H. Definitions of Normal Liver Fat and the Association of Insulin Sensitivity with Acquired and Genetic NAFLD—A Systematic Review. Int. J. Mol. Sci. 2016, 17, 633. [CrossRef] [PubMed]

21. Van Werven, J.R.; Marsman, H.A.; Nederveen, A.J.; Smits, N.J.; ten Kate, F.J.; van Gulik, T.M.; Stoker, J. Assessment of Hepatic Steatosis in Patients Undergoing Liver Resection: Comparison of US, CT, T1-weighted Dual-Echo MR Imaging, and Point-resolved 1H MR Spectroscopy. Radiology 2010, 256, 159-168. [CrossRef]

22. Chen, D.L.; Liess, C.; Poljak, A.; Xu, A.; Zhang, J.; Thoma, C.; Trenell, M.; Milner, B.; Jenkins, A.B.; Chisholm, D.J.; et al. Phenotypic characterization of insulin-resistant and insulin-sensitive obesity. J. Clin. Endocrinol. Metab. 2015, 100, 4082-4091. [CrossRef]

23. Snedecor, G.W.; Cochran, W.G. Statistical Methods, 8th ed.; Iowa State University Press: Iowa City, IA, USA, 1989; ISBN 978-0-8138-1561-9.

24. Games, P.A.; Howell, J.F. Pairwise Multiple Comparison Procedures with Unequal N's and/or Variances: A Monte Carlo Study. J. Educ. Behav. Stat. 1976, 1, 113-125.

25. Cleasby, M.E.; Jamieson, P.M.; Atherton, P.J. Insulin resistance and sarcopenia: Mechanistic links between common co-morbidities. J. Endocrinol. 2016, 229, R67-R81. [CrossRef] [PubMed]

26. Lee, M.J.; Kim, E.; Bae, S.; Choe, J.; Jung, C.H.; Lee, W.J.; Kim, H. Protective Role of Skeletal Muscle Mass against Progression from Metabolically Healthy to Unhealthy Phenotype. Clin. Endocrinol. 2019, 90, 102-113. [CrossRef] [PubMed]

27. Samocha-Bonet, D.; Chisholm, D.J.; Tonks, K.; Campbell, L.V.; Greenfield, J.R. Insulin-sensitive obesity in humans-A "favorable fat" phenotype? Trends Endocrinol. Metab. 2012, 23, 116-124. [CrossRef] [PubMed]

28. Stefan, N.; Fritsche, A.; Schick, F.; Haring, H.U. Phenotypes of prediabetes and stratification of cardiometabolic risk. Lancet Diabetes Endocrinol. 2016, 4, 789-798. [CrossRef]

29. Roberts, R.; Hodson, L.; Dennis, A.L.; Neville, M.J.; Humphreys, S.M.; Harnden, K.E.; Micklem, K.J.; Frayn, K.N. Markers of de novo lipogenesis in adipose tissue: Associations with small adipocytes and insulin sensitivity in humans. Diabetologia 2009, 52, 882-890. [CrossRef]

30. Fabbrini, E.; Yoshino, J.; Yoshino, M.; Magkos, F.; Tiemann Luecking, C.; Samovski, D.; Fraterrigo, G.; Okunade, A.L.; Patterson, B.W.; Klein, S. Metabolically normal obese people are protected from adverse effects following weight gain. J. Clin. Investig. 2015, 125, 787-795. [CrossRef] 